\title{
Lateral variations of $P_{n}$ velocity and anisotropy in Taiwan from travel-time tomography
}

\author{
Chau-Huei Chen ${ }^{1}$, Yue-Haun Chen ${ }^{1}$, Horng-Yuan Yen ${ }^{2}$, and Guey-Kuen Yu ${ }^{3}$ \\ ${ }^{1}$ Institute of Seismology, National Chung Cheng University, Chia-Yi, Taiwan \\ ${ }^{2}$ Department of Earth Science, National Central University, Chung-Li, Taiwan \\ ${ }^{3}$ Department of Civil Engineering, Van Nung Institute of Technology, Chung-Li, Taiwan
}

(Received August 20, 2002; Revised April 9, 2003; Accepted April 9, 2003)

\begin{abstract}
In this study, the $P$ arrivals of 1726 ray paths with the epicentral distances longer than $200 \mathrm{~km}$ from 539 earthquakes that occurred in Taiwan are used to investigate the variation of $P_{n}$ velocity. The results show that the lateral variation of $P_{n}$ velocity in Taiwan is quite similar to the pattern of gravity anomaly and strongly related to several features of Taiwan's geological structure. The crust is a little thicker (about $39 \mathrm{~km}$ ) in the Central Range and somewhat thinner toward the east and west. A relatively thin crust (about $35 \mathrm{~km}$ ) is obtained in the area of Peikang High; however, an unexpected thick crust of greater than $40 \mathrm{~km}$ is also found at the corner of southwestern Taiwan. The degree of anisotropy of $P_{n}$ velocity is found less than $10 \%$ and the fast direction is generally in the E$\mathrm{W}$ direction. This direction is parallel to the axis of compressional stress or the direction of plate motion, indicating that the anisotropy results from the deformation of the upper mantle.
\end{abstract}

Key words: $P_{n}$, anisotropy, tomography.

\section{Introduction}

Taiwan is located at the boundary between the Philippine Sea and Eurasian plates, and one of the most spectacular arccontinent collisions occurs there. A better understanding of the subterranean structure of this area is an important topic for geological and geophysical scientists; however, from the past studies, there is little agreement on the dynamic processes responsible for the crust-mantle structure of the island and surrounding areas (Suppe, 1981, 1985; Rau and Wu, 1995). Lateral variation of $P_{n}$ velocity is associated with the changes of the temperature, pressure, and material in upper mantle, while variation in crustal thickness has resulted from many different factors including crustal extension or compression, isostatic forces, and magma intrusion (Black and Braile, 1982). Thus, knowledge about the crustal thickness and $P_{n}$ velocity can provide valuable information on crustal deformation, and help us to infer the tectonic evolution of the study area.

In Taiwan, an average of $P_{n}$ velocity with $7.8 \mathrm{~km} / \mathrm{s}$ was first given by Yeh and Tsai (1981). Later, Huang et al. (1998) presented the regionalized $P_{n}$ velocities with $8.2 \mathrm{~km} / \mathrm{s}, 7.9$ $\mathrm{km} / \mathrm{s}$, and $8.0 \mathrm{~km} / \mathrm{s}$ for the regions of the Taiwan Strait, Taiwan Island, and Eastern Coastal Range, respectively. Lateral variations of the crustal thickness and upper mantle $P$-wave velocity were estimated by several studies from 3-D velocity inversion (Chen et al., 1994; Rau and Wu, 1995; Ma et al., 1996).

The anisotropic properties in the upper mantle are considered to be related to the shear stress of plate motion (Raitt et al., 1969; Okal and Talandier, 1980; Hearn, 1984). Kuo et

Copy right(c) The Society of Geomagnetism and Earth, Planetary and Space Sciences (SGEPSS); The Seismological Society of Japan; The Volcanological Society of Japan; The Geodetic Society of Japan; The Japanese Society for Planetary Sciences. al. (1994) have observed a certain degree of anisotropy for $P_{n}$ velocity in upper mantle of the northern Taiwan. In our current study, the travel times of $P_{n}$ are used to derive better images of the lateral variations of the $P_{n}$ velocity and its anisotropy. Meanwhile, the corresponding crustal thickness is also estimated. From these results, a better explanation of the tectonic evolution in Taiwan area is inferred.

\section{Tectonic Setting}

The geological structures of Taiwan trend mainly in a NNE-SSW direction as shown in the simplified geological map (Fig. 1). These trends are parallel to the main topographic trends. The topography of Taiwan is dominated by the Central Range where pre-Tertiary metamorphic complexes are exposed. They are most probably exhumed lower crustal material raised to the upper level as a result of recent orogeny (Ho, 1986; Lin, 2000). East of the metamorphic complex is the Coastal Range. These layers are thrust up along a series of echelon faults, striking about $\mathrm{N} 30^{\circ} \mathrm{E}$, with a small angle to the dominant structural trend of the island. These thrust layers were successively accreted to the island, beginning around 4-6 million years before present (Lee et al., 1991). The Longitudinal Valley separates the Coastal Range from the Central Range to the west, and is considered to be the suture that juxtaposes older continental rocks and young island arc materials. It also separates the highly seismic Coastal Range (Wu et al., 1989) from the relatively aseismic Central Range. To the west of the preTertiary metamorphic complex are the main Central Range, the Foothills and the Coastal Plain. The Peikang high, as a pre-Tertiary basement, separates the western Taiwan into two parts: the pro-orogenic sedimentary material in northwestern Taiwan were formed in relatively shallow shelf envi- 


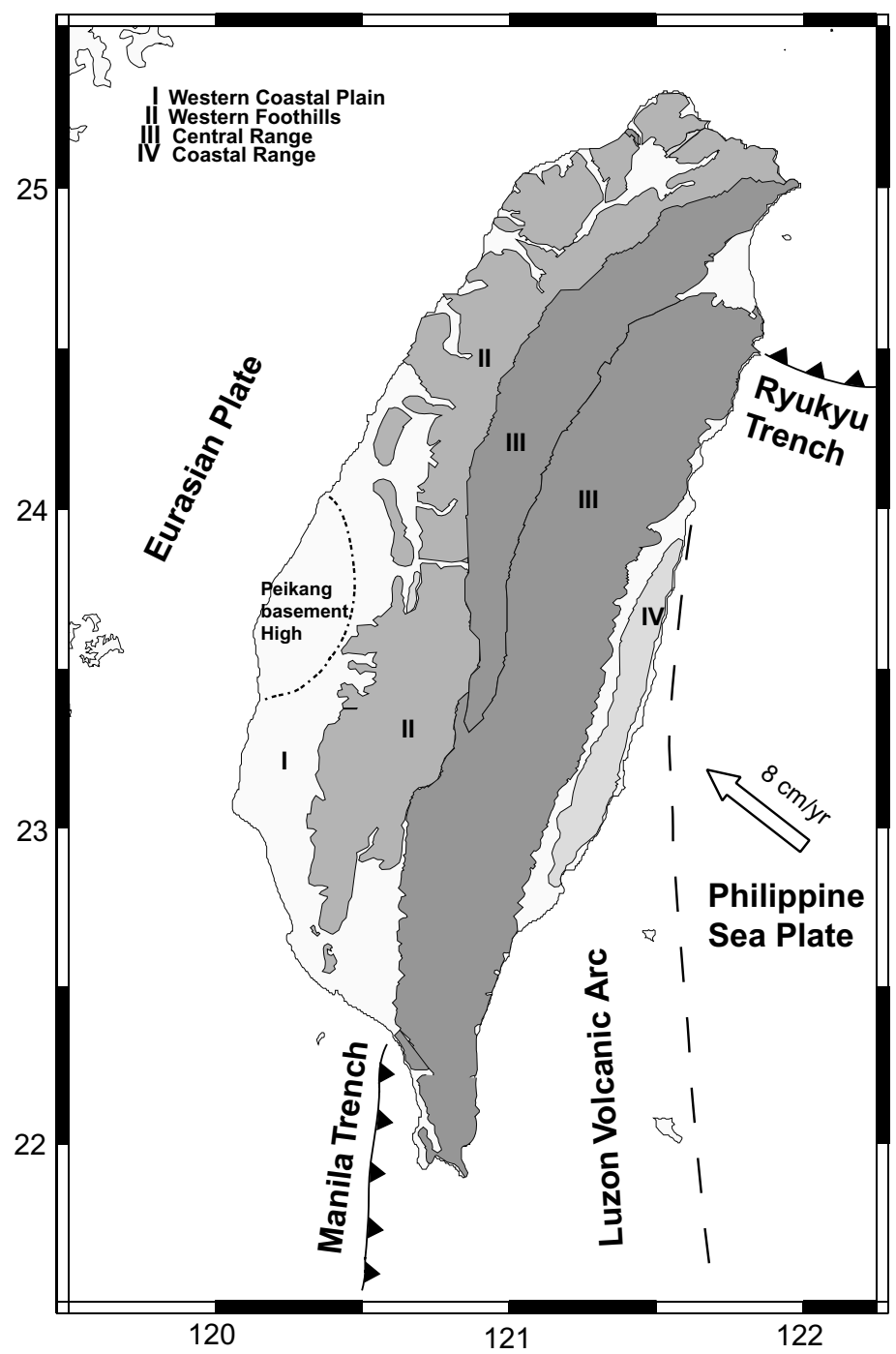

Fig. 1. A simplified structural geology map of Taiwan showing: (a) The regional tectonic stress due to the convergence of the Philippine Sea and the Eureasia Plates. (b) The major geological regimes in Taiwan: I. Western Coastal Plain, II. Western Foothills, III. Central Range (forms the backbone of Taiwan), and IV. Coastal Range. The dashed region on the western coast shows the approximate location of the Peikang High (PKH), which is the Tertiary basement high detected from seismic reflection mapping.

ronments, whereas the material in the south-western Taiwan were formed along the former continental slope, as a part of the passive margin of southeastern China. The Coastal Plain of western Taiwan is composed of Quaternary alluvial deposits, at the shallow depths. The Neogene strata underneath the alluvial are gently folded and getting thinner to the west.

\section{Data and Methodology}

In this study, the $P$-arrivals of earthquakes in Taiwan area as recorded by the Central Weather Bureau Seismic Network (CWBSN) during the period between 1993 and 2001 have been used. To obtain a high quality data set and ensure that the $P$-arrivals were $P_{n}$ phases, a few criteria for selecting the final data were followed: (a) the epicentral distance is greater than $200 \mathrm{~km}$; (b) the focal depth is less than $25 \mathrm{~km}$; (c) the errors of hypocenter determination are within $3 \mathrm{~km}$ in horizontal, and $5 \mathrm{~km}$ in vertical; (d) the $P_{n}$ arrivals are picked with errors less than \pm 0.1 s (i.e. the weightings assigned by CWB of observations belong to 0,1 , and 2 only). Based on these criteria, a total of 1768 ray paths from 539 events are selected as the data set for $P_{n}$ velocity inversion. The ray paths shown in Fig. 2 are quite well distributed in crossover the Taiwan area.

In order to investigate the lateral variation of $P_{n}$ velocity, the area of Taiwan $\left(21.6^{\circ} \mathrm{N}\right.$ to $25.6^{\circ} \mathrm{N}, 119.8^{\circ} \mathrm{E}$ to $\left.122.2^{\circ} \mathrm{E}\right)$ is divided into 240 blocks, thus each block size is $0.2^{\circ} \times$ $0.2^{\circ}$. The total travel time of each path is the sum of the time across the blocks plus the time-term corrections for the station and source as shown in the following equation (Zhao and Xie, 1993):

$$
t_{i j} \approx \frac{X_{i j}}{V_{i j}^{0}}=\sum \Delta_{i j k} S_{k}+a_{i}+b_{j}
$$

where $t_{i j}$ is the travel time of the path from event $i$ to station $j ; X_{i j}$ is the epicentral distance of the path; $V_{i j}^{0}$ is the average $P_{n}$ velocity of the path (Zhao and Xie, 1993); $\Delta_{i j k}$ is the length of the ray path in block $k$; $S_{k}$ is the slowness of block $k ; a_{i}$ and $b_{j}$ are the time-term corrections for station and source. If the azimuthal anisotropy is taken into account, 


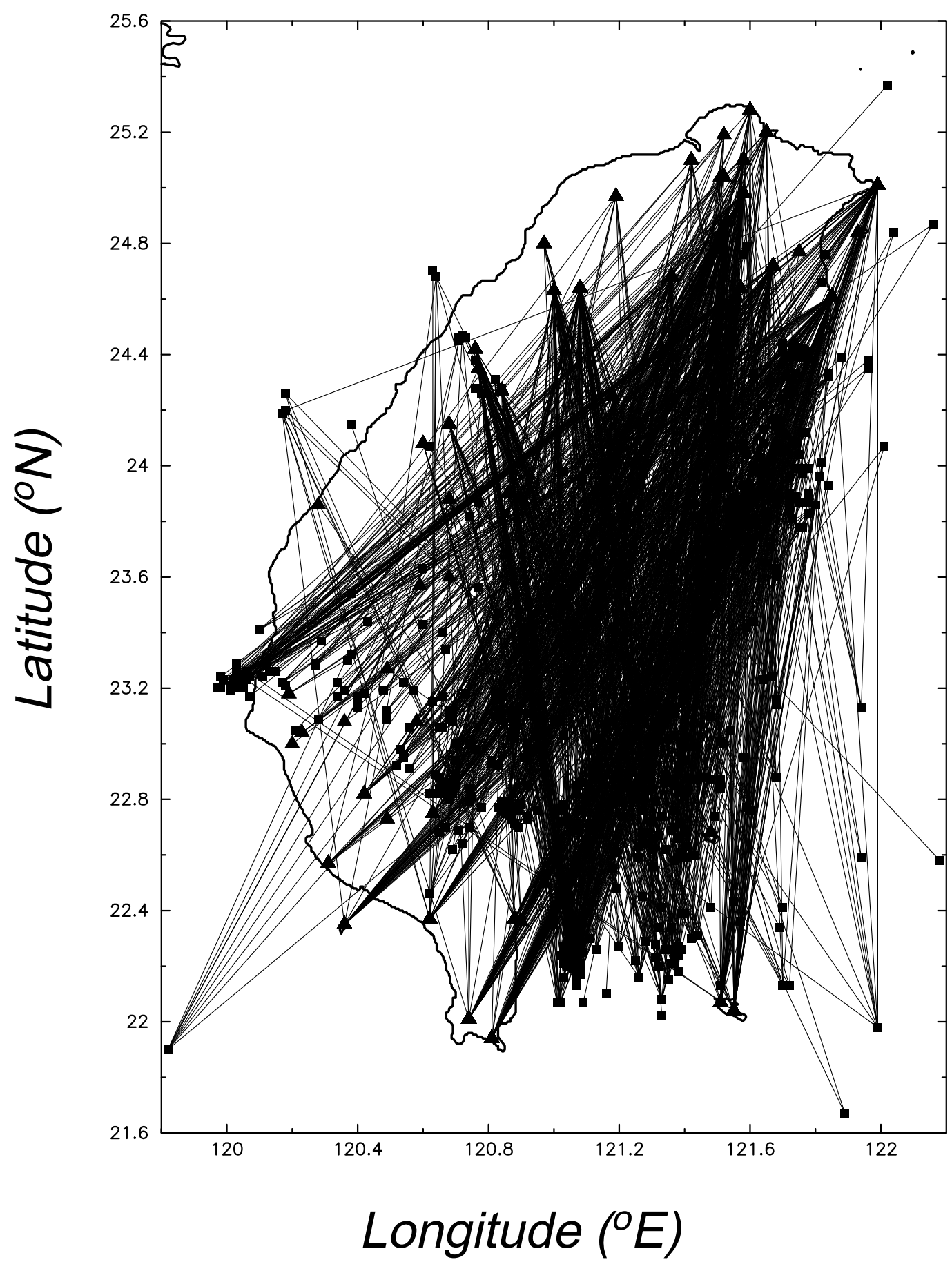

Fig. 2. Ray paths. Solid triangle and square represent the locations of seismic stations and epicenters, respectively.

then the equation becomes (Hearn, 1996)

$\frac{1}{V_{i j}^{o}}=\frac{1}{X_{i j}} \sum\left(S_{k}+A_{k} \cos 2 \phi+B_{k} \sin 2 \phi\right) * \Delta_{i j k}+\operatorname{Res}_{i j}$

where, $A_{k}$ and $B_{k}$ are the anisotropic coefficients and $\phi$ is the angle of fast direction as measured from the north. The quantity $\left(A_{k}^{2}+B_{k}^{2}\right)^{1 / 2}$ represents the magnitude of anisotropy and $\phi=\frac{1}{2} \tan ^{-1}\left(B_{k} / A_{k}\right)$.

After rearranging the Eq. (2) and simplifying, we obtain

$$
\frac{1}{V_{i j}^{o}}=\frac{\sum \Delta_{i j k}\left(S_{k}+A_{k} \cos 2 \phi+B \sin 2 \phi\right)}{X_{i j}}+R_{i j}
$$

where

$$
R_{i j} \approx \frac{\delta a_{i}+\delta b_{j}}{X_{i j}}
$$

is the error between theoretical calculations and observations. Solving Eq. (3) by the back-projection method (Xie and Mitchell, 1990), the values of $P_{n}$ velocity and the coefficients of anisotropic terms are obtained. The resolution of the inversion results is expressed as the Point Spread Function (PSF) (Zhao and Xie, 1993). Assuming that the traveltime residual of the $P_{n}$ velocity inversion predominantly results from the lateral variation of the Moho depth (Zhao and Xie, 1993; Baumont et al., 2001), we can solve for $\delta a_{i}$ and 


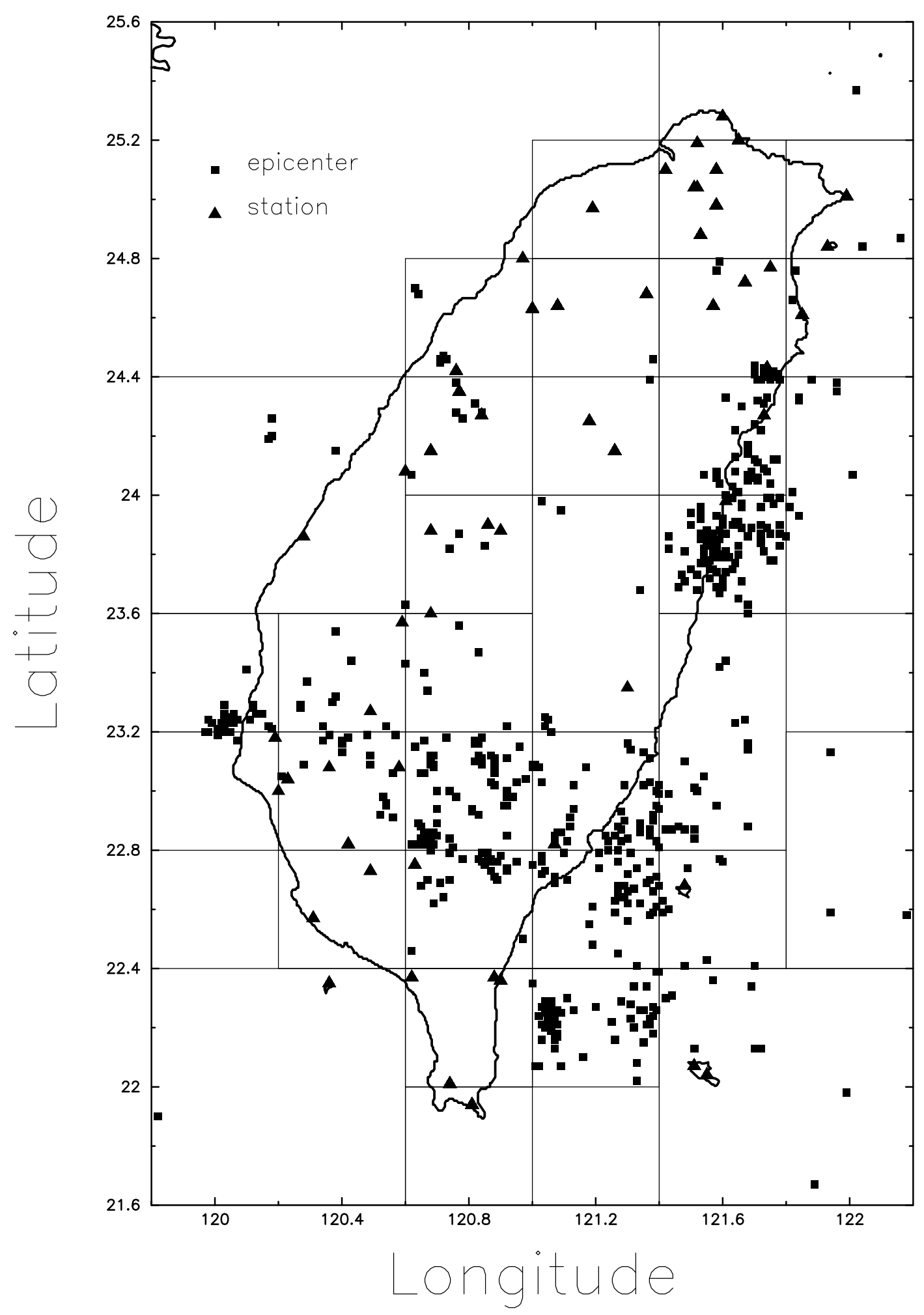

Fig. 3. Sub-regions used in the Moho depth inversion.

$\delta b_{i}$ with the known $R_{i j}$. With the improvements in estimation Moho depth, we recalculate the $P_{n}$ velocities. Through an iteration procedure we are able to obtain $P_{n}$ velocity and Moho depth with minimum travel-time residuals. For making this inversion overdetermined, and reducing errors in original times, in event locations and arrival-time readings, we merge the unknowns $\delta a_{i}$ and $\delta b_{i}$ into a new set of unknowns (Zhao and Xie, 1993) according to the distributions of stations and epicenters (Fig. 3), and the Moho depth in the subregion is assumed constant.

\section{Results and Discussion}

Before inversion, the appropriate initial values of the crustal thickness $(H)$, the crustal $P$ velocity $\left(V_{c}\right)$, and the upper mantle $P$ velocity $\left(V_{m}\right)$ have to be estimated. In doing this, the regression method presented by Zhao and Xie 
a.

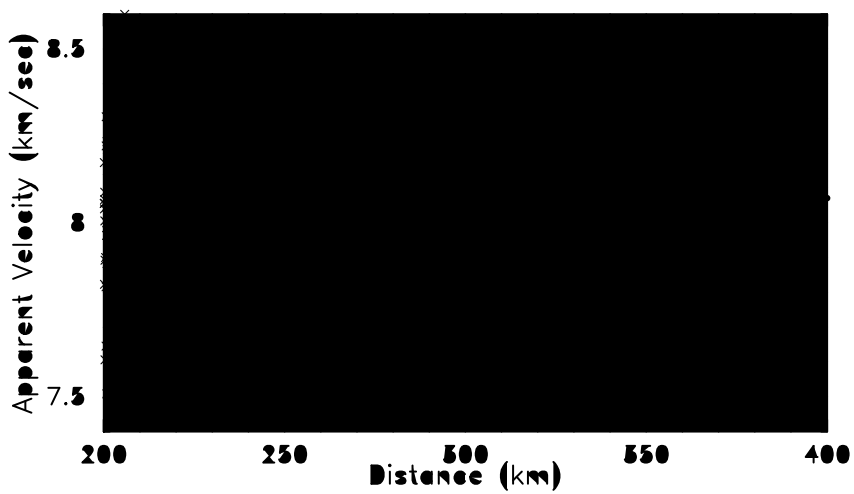

b. $\quad$ Fixed $V m=7.8(\mathrm{~km} / \mathrm{sec})$

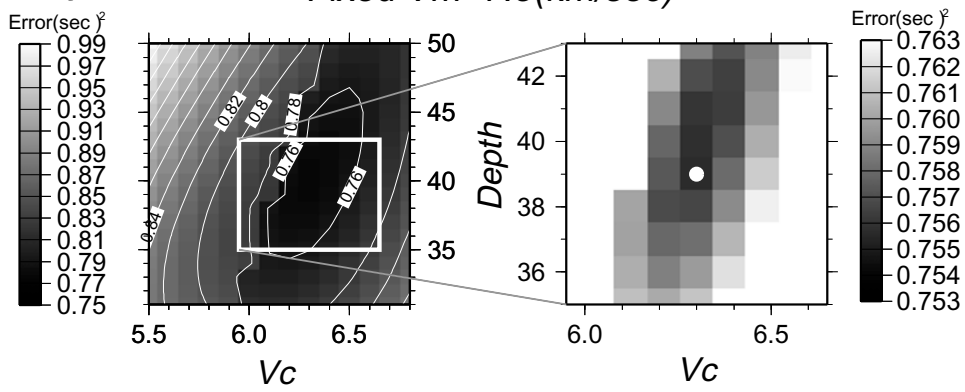

Fig. 4. (a) $P_{n}$ travel time curve (bold line) derived from linear regression of arrival time data used in this study. Two thin lines represent the standard errors in fitting. A slight dependence of velocity on the travel distance indicates that the ray paths used in this study do not penetrate the deep mantle. (b) The distribution of RMS travel time residual for various combination of the average crustal $P$ velocity $\left(V_{c}\right)$ and Moho depth with fixed mantle $P$ velocity $\left(V_{m}\right)$.
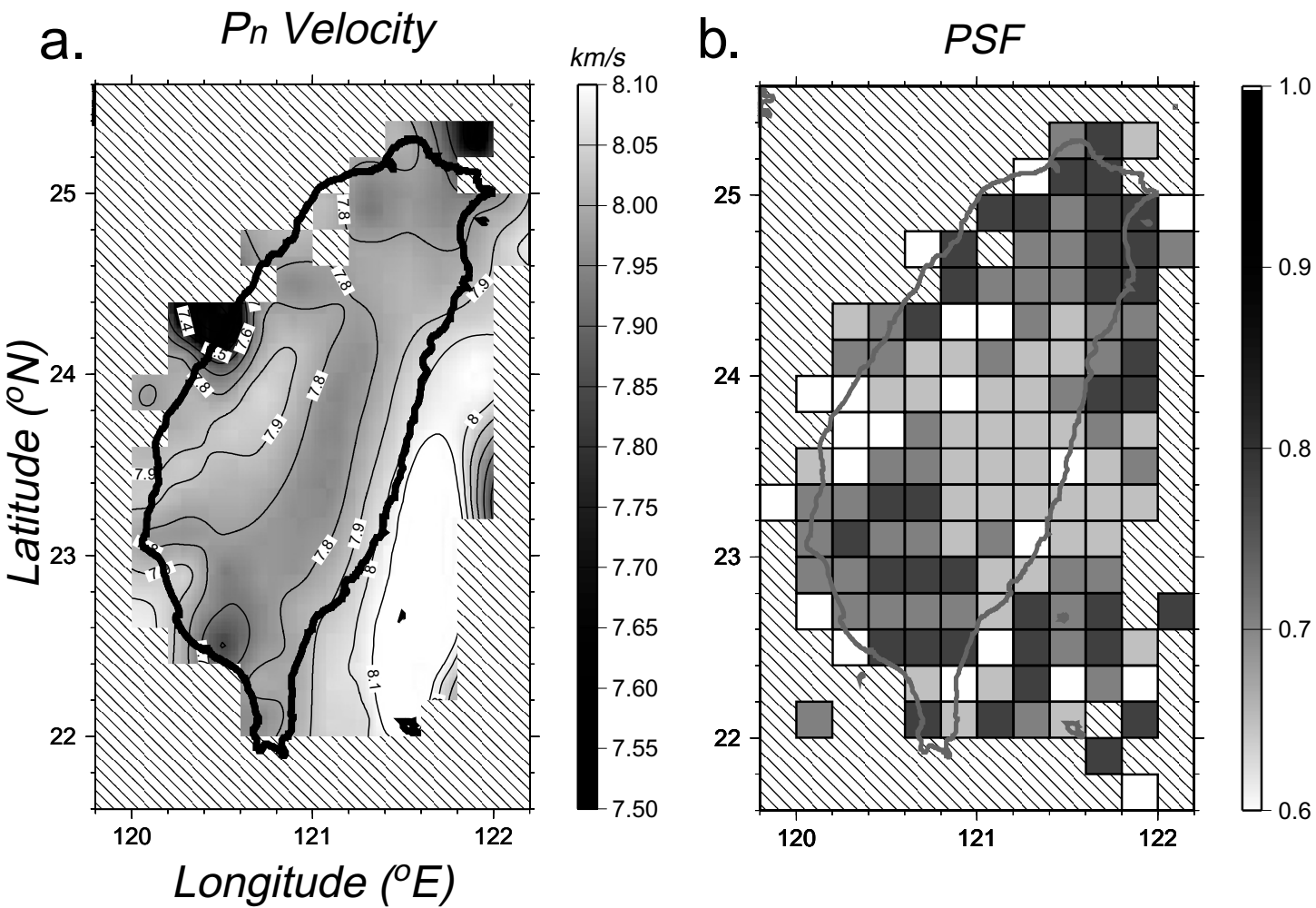

Fig. 5. (a) The $P_{n}$ velocity distribution derived from travel time tomography. (b) The PSF distributions for model blocks. Note that the blocks with PSF values lower than 0.6 are represented by oblique line. It shows that the inversion can resolve the dimension roughly the same as that of the Taiwan Island. 

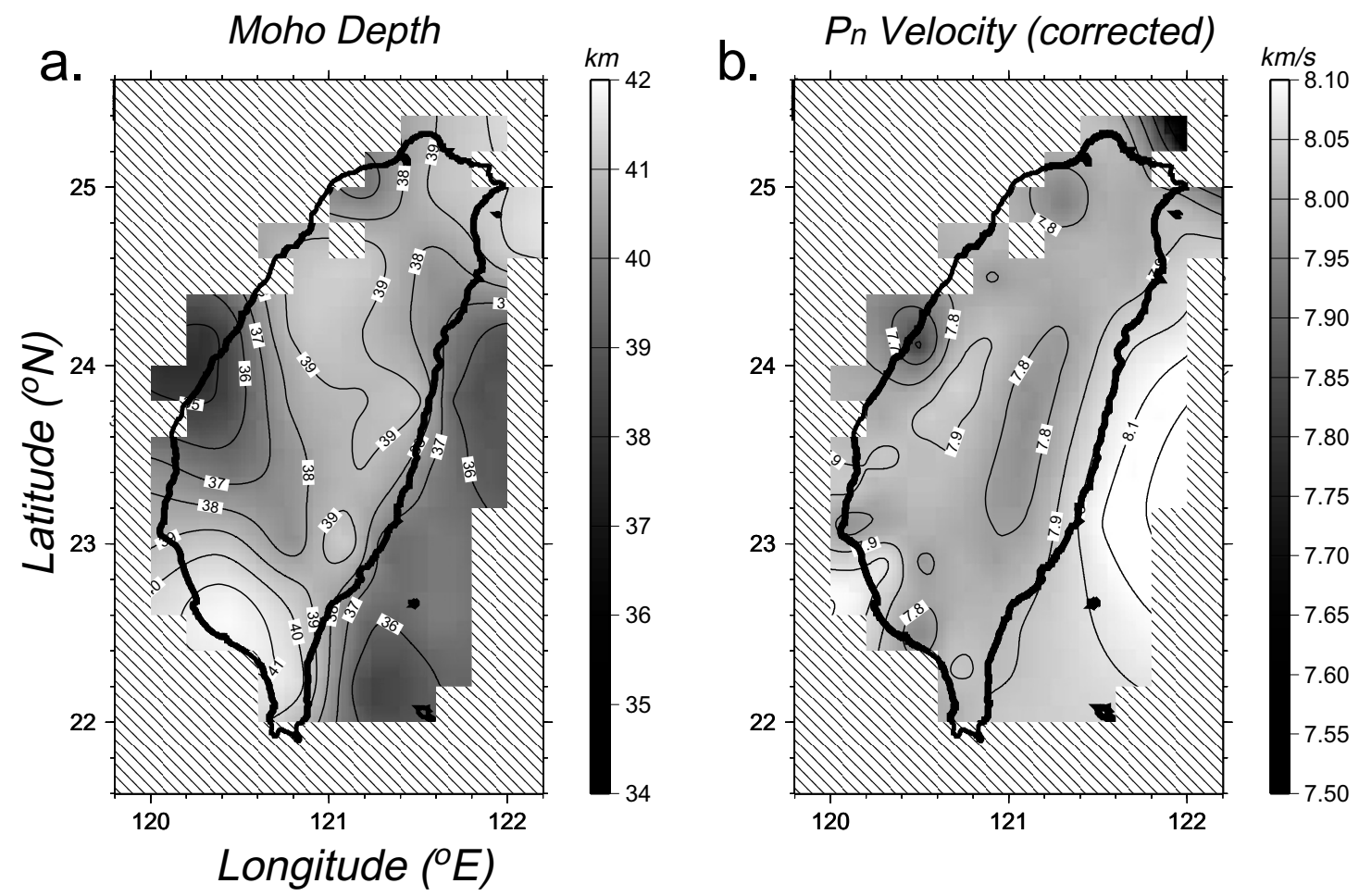

Fig. 6. (a) The Moho depth distribution. (b) The corrected $P_{n}$ velocity distribution.

(1993) is applied to estimate the upper mantle $P$ velocity $\left(V_{m}\right)$ (Fig. 4(a)); then, fixing $V_{m}$, and taking various combinations of $H$ and $V_{c}$, the optimal values of $H$ and $V_{c}$ are obtained when the minimum travel-time residual of inversion is found (Fig. 4(b)). According to these procedures, the values of $7.8 \mathrm{~km} / \mathrm{s}, 6.3 \mathrm{~km} / \mathrm{s}$, and $39 \mathrm{~km}$ for $V_{m}, V_{c}$, and $H$, are obtained, respectively. These values are used as the initial values for inversion of Eq. (3). The lateral variation of $P_{n}$ velocity, as shown in Fig. 5(a), is derived by the back-projection method. The spatial resolution at a given cell can be estimated by the point-spreading function (PSF) calculated for the cell (e.g. Humphreys and Clayton, 1988; Xie and Mitchell, 1990; Zhao and Xie, 1993). We calculated the PSF of each block and found that the spreading of PSF is generally within about $0.3^{\circ}$ (three blocks). For a full understanding of the distribution of the degrees of resolutions of the blocks in the entire research area, Figure 5(b) shows the PSF values of each central block (which is similar to the diagonal element of the resolution matrix in the least square inversion). The path average travel-time residual after $P_{n}$ velocity inversion is roughly $0.753 \mathrm{~s}$ as shown in Fig. 4(b). Using Eq. (4), the variation of crustal thickness in Taiwan is calculated and shown in Fig. 6(a). Based on this crustal thickness the lateral variation of $P_{n}$ velocity is also corrected and shown in Figure 6(b). The path average traveltime residual $(0.172 \mathrm{~s})$ after Moho depth correction is $77 \%$ less than that before inversion. The distribution of corrected $P_{n}$ velocity agrees well with the pattern of gravity anomaly given by Yen et al. (1998). A zone, covering most of the Central Range, is found to have a crustal thickness of about $39 \mathrm{~km}$ and $P_{n}$ velocity of about $7.8 \mathrm{~km} / \mathrm{s}$, suggesting that the low velocity observation in the Central Range may not only reflect the high thermal gradient on, but also the variation in crustal thickness. The crust becomes thinner in both western and eastern Taiwan as compared with the Central Range. The area of Peikang High, which played an important role in tectonic evolution of Taiwan during late Miocene, also has a relative thinner crust (about $35 \mathrm{~km}$ ) compared to its surroundings. In eastern offshore region, the thinner crust represents the transition structure of the Philippine Sea Plate. A crustal thickness greater than $40 \mathrm{~km}$ at the corner of southwestern Taiwan has probably resulted from the spreading of the South China Sea in the past, and the Eurasian Plate was dragged down to the mantle (Chemenda et al., 1995, 1996). The deeper Moho depth is also shown by wide-angle reflection profile analysis (Shih et al., 2001).

Figure 7(a) shows the distribution of anisotropy for $P_{n}$ velocity in Taiwan area. Figures 7(b) and 7(c) show the error distributions of the anisotropic coefficient components $A_{k}$ and $B_{k}$. From Fig. 7(a), it is easily seen that the fast directions for $P_{n}$ velocity are nearly in the E-W direction. The degree of anisotropy is less than $10 \%$, and the anisotropy in western Taiwan is a little greater than that in eastern. Although a few inconsistent directions are found, but, in general, the fast direction is almost parallel to the axis of compressional stress or the direction of plate motion. This result is consistent with the result obtained from a study of shear wave splitting in western Taiwan (Chen and Yen, 1998). Similar results have also given by Hearn (1996) in California.

\section{Conclusion}

From a thorough study on the distributions of the crustal thickness, $P_{n}$ velocity, and anisotropy in Taiwan area, a few conclusions are given below:

(1) The variations of crustal thickness and $P_{n}$ velocity 
a. Fast Direction of Pn Velocity
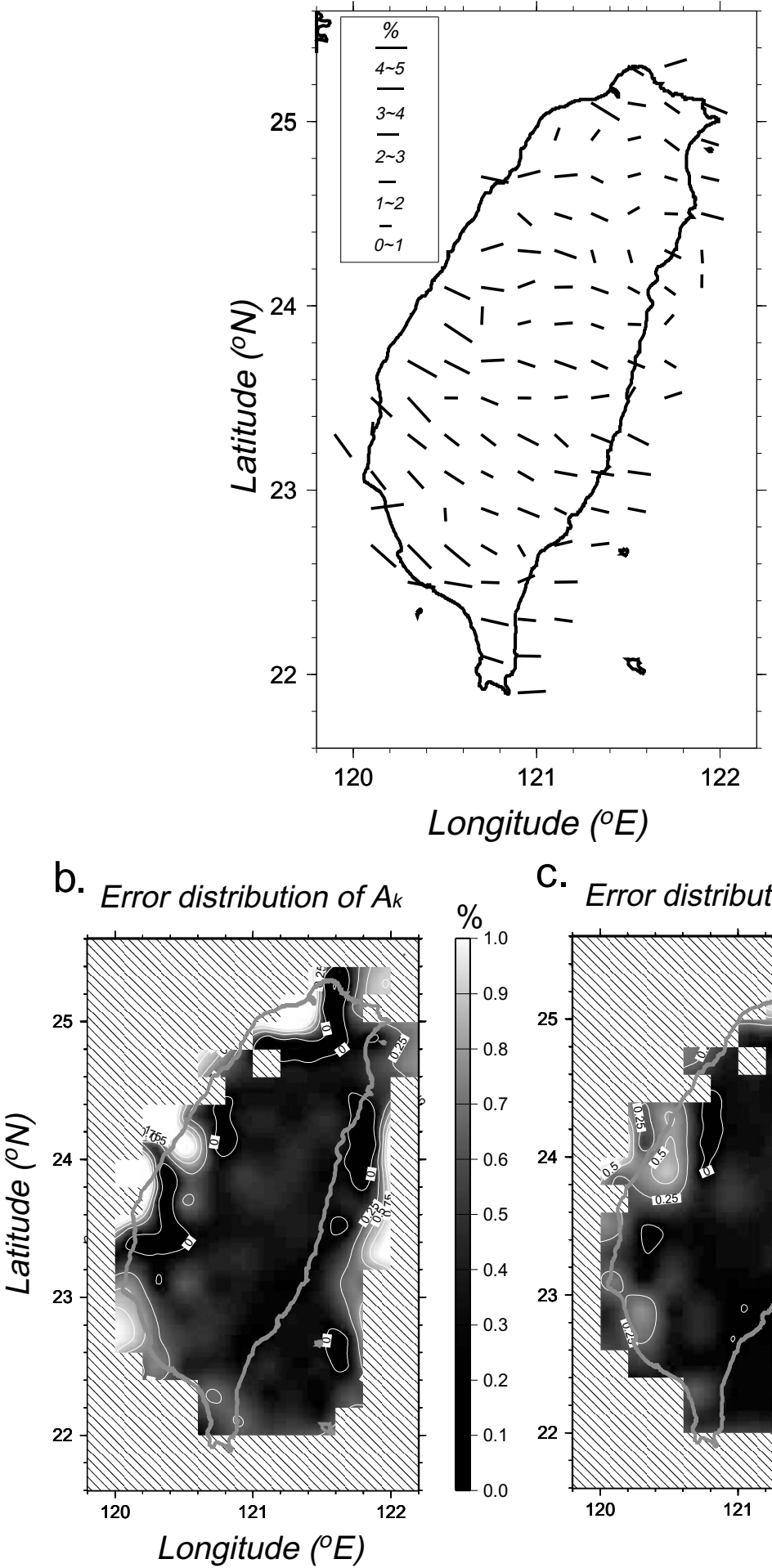

C. Error distribution of $B_{k}$

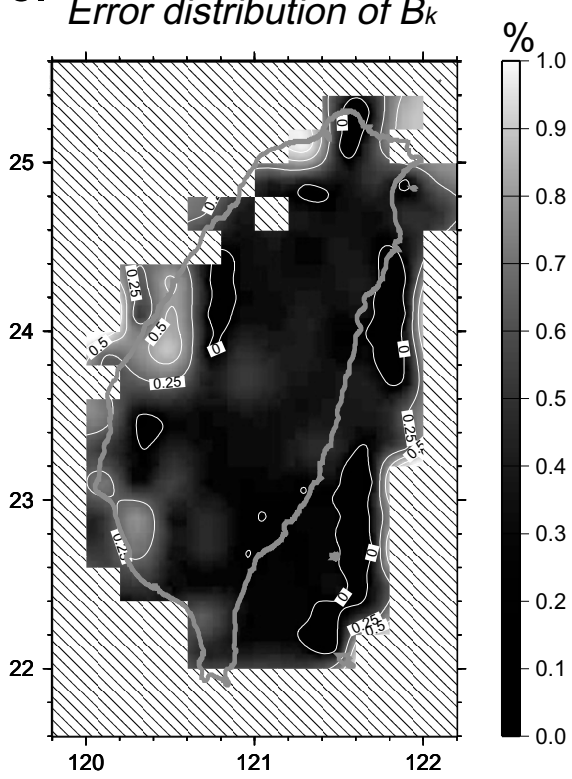

Fig. 7. (a) Distribution of the direction of fast $P_{n}$ velocity. The length of solid line represents the magnitude of anisotropy. The errors of the anisotropic coefficients $\left(A_{k}\right.$ and $\left.B_{k}\right)$ are also shown in (b) and (c).

are quite similar to the distribution of gravity anomaly and strongly related to the feature of geological structures in Taiwan.

(2) The area of Peikang High, an important geological structure in western Taiwan, has a relative thinner crust to its surroundings. An unexpected crustal thickness of greater than $40 \mathrm{~km}$ is also found at the corner of southwestern Tai- wan.

(3) The degrees of anisotropy for $P_{n}$ velocity are less than $10 \%$, and the fast direction is nearly $\mathrm{E}-\mathrm{W}$ in general. This direction is parallel to the axis of compressional stress or the direction of plate motion, indicating that the anisotropy results from the deformation of upper mantle beneath Taiwan area. 
Acknowledgments. The authors would like to thank the editor and two anonymous reviewers for their constructive comments on the manuscript. We also would like to appreciate the Central Weather Bureau and Dr. Jiakang Xie for providing us the data and inversion code. This study was financially supported by grants from the National Science Council, Republic of China and the Central Weather Bureau under contract numbers with NSC 91-2119-M-194-006 and MOTC-CWB-91-E-23.

\section{References}

Baumont, D., A. Paul, G. Zandt, and S. L. Beck, Inversion of $\mathrm{P}_{n}$ travel times for lateral variations of Moho geometry beneath the Central Andes and comparison with the receiver functions, Geophys. Res. Lett., 28, 1663 1666, 2001.

Black, P. R. and L. W. Braile, $\mathrm{P}_{n}$ velocity and cooling of the continental lithosphere, J. Geophys. Res., 87, 10557-10568, 1982.

Chemenda, A. I., M. Mattauer, and A. N. Bokun, A mechanism for syncollisional deep rock exhumation and associated normal faulting: results from physical modeling, Earth Planet Sci. Lett., 132, 225-232, 1995.

Chemenda, A. I., M. Mattauer, and A. N. Bokun, Continental subduction and a mechanism for exhumation of high-pressure metamorphic rocks: new modeling and field data from Oman, Earth Planet Sci. Lett., 143 173-182, 1996.

Chen, C. H. and H. J. Yen, A preliminary study on crustal anisotropy in Chia-Nan area of Taiwan, TAO, 9, 573-588, 1998.

Chen, C. H., W. H. Wang, and Y. H. Yeh, 3-D velocity structure in Taiwan area: A tectonic implication of continent-arc collision (abstract), Eos Trans. AGU, Fall Meet. Suppl., 75(44), 645, 1994.

Hearn, T., $\mathrm{P}_{n}$ travel time in southern California, J. Geophys. Res., 89, 1843 $1855,1984$.

Hearn, T., Anisotropic $\mathrm{P}_{n}$ tomography in the western United States, J. Geophys. Res., 101, 8403-8414, 1996.

Ho, C. S., A synthesis of the geological evolution of Taiwan, Mem. Geol. Soc. China, 8, 15-29, 1986.

Huang, B. S., K. C. Chen, and H. Y. Yen, Velocity of $\mathrm{P}_{n}$-waves in the Taiwan Strait and its surrounding area from regional earthquakes, TAO, 9, 473486, 1998.

Humphreys, E. and R. W. Clayton, Adaptation of back projection tomography to seismic travel time problem, J. Geophys. Res., 93, 1073-1086, 1988.

Kuo, B. Y., C. C. Chen, and T. C. Shin, Split S waveforms observed in northern Taiwan: implications for crustal anisotropy, Geophys. Res. Lett.,
21, 1491-1494, 1994.

Lee, T. Q., C. Kissel, E. Barrier, C. Laj, and W. R. Chi, Paleomagnetic evidence for a diachronic clockwise rotation of the Coastal Range, eastern Taiwan, Earth Planet Sci. Lett., 104, 245-257, 1991.

Lin, C. H., Thermal modeling of continent subduction and exhumation constrained by heat flow and seismicity in Taiwan, Tectonophysics, 324, 189-201, 2000.

Ma, K. F., J. H. Wang, and D. Zhao, Three-dimensional seismic velocity structure of the crust and uppermost mantle beneath Taiwan, J. Phys. Earth, 44, 85-105, 1996.

Okal, E. A. and J. Talandier, Rayleigh wave phase velocities in French Polynesia, Geophys. J. R. Astron. Soc., 63, 719-733, 1980.

Raitt, R. W., G. G. Shor, T. J. G. Francis, and G. B. Morris, Anisotropy of the Pacific upper mantle, J. Geophys. Res., 74, 3095-3109, 1969.

Rau, R. T. and F. T. Wu, Tomographic imaging of lithospheric structure under Taiwan, Earth Planet. Sci. Lett., 133, 517-532, 1995.

Shih, R. C., S. C. Shin, C. H. Lin, Y. H. Yeh, and H. Y. Yen, 2D and 3D deep crustal structure in southern Taiwan, Proceeding of 4th Cross-Strait Seismological Symposium, Da-si, Taiwan, 183-186, 2001.

Suppe, J., Mechanics of mountain building and metamorphism in Taiwan, Mem. Geol. Soc. China, 4, 67-89, 1981.

Suppe, J., Principles of Structural Geology, 537 pp, Prentice-Hall Inc., N.J., 1985.

Wu, F. T., K. C. Chen, J. H. Wang, R. McCaffrey, and D. Salzberg, Focal mechanisms of recent large earthquakes and the nature of faulting in the Longitudinal Valley of eastern Taiwan, Proc. Geol. Soc. China, 32, 157$177,1989$.

Xie, J. and B. J. Mitchell, A back-projection method for imaging large-scale lateral variations of $\mathrm{Lg}$ coda $\mathrm{Q}$ with application to continental Africa, Geophys. J. Int., 100, 161-181, 1990.

Yeh, Y. H. and Y. B. Tsai, Crustal structure of central Taiwan from inversion of $P$-wave arrival times, Bull. Inst. Earth Sci., Academia Sinica, 1, 83102, 1981

Yen, H. Y., Y. H. Yeh, and F. T. Wu, Two-Dimensional crustal structure of Taiwan from gravity data, Tectonics, 17, 104-111, 1998.

Zhao, L. S. and J. Xie, Lateral variations in compressional velocities beneath Tibetan plateau from $\mathrm{P}_{n}$ travel Time tomography, Geophys. J. Int., 115, 1070-1084, 1993

C.-H. Chen (e-mail: seichen@eq.ccu.edu.tw), Y.-H. Chen, H.-Y. Yen, and G.-K. Yu 